\title{
Patient Perspectives on Discussions of Electronic Cigarettes in Primary Care
}

\author{
Mark P. Doescher, MD, MSPH, Ming Wu, MD, PhD, Elizabeth Rainwater, MD, \\ Ali S. Khan, and Dorothy A. Rhoades, MD, MPH
}

Purpose: Patient preferences regarding the role of the primary care provider (PCP) in discussing electronic cigarette (e-cigarette) use are unknown.

Methods: We administered a cross-sectional survey to 568 adult patients in a family medicine clinic to explore e-cigarette use, sources of information on e-cigarettes, perceived knowledge about e-cigarette health effects, views regarding PCP knowledge of e-cigarettes, interest in discussing e-cigarettes with PCPs and preferred format for e-cigarette information. We performed $\chi^{2}$ testing with a 2 -tailed $P<.05$ to assess associations between e-cigarette use and these measures.

Results: The prevalence of e-cigarette use was $10 \%$ for recent $(\leq 30$ days) use and $29 \%$ for nonrecent (>30 days) use. Prevalence was significantly higher among those who were younger, less educated, or smoked cigarettes, but did not vary by sex or self-reported health status. Roughly one quarter of participants believed they were knowledgeable about the health effects of e-cigarettes, secondhand smoke, and quitting cigarettes. Sources of e-cigarette information included television advertisements (56.6\%), friends and family (49.9\%), or e-cigarette shops (25.5\%), but included physician offices much less frequently (6.0\%). Although 30.2\% disagreed that their PCP knew a lot about e-cigarettes, $62.0 \%$ were comfortable discussing e-cigarettes with their PCP. However, only $25 \%$ of all patients wanted their PCP to discuss e-cigarettes with them, but $62.0 \%$ of recent e-cigarette users wanted such a discussion. Most preferred a brief discussion or handout to a lengthy discussion.

Conclusion: PCPs were infrequent sources of information for patients regarding e-cigarette use. PCPs need evidence-based strategies to help them address e-cigarettes in primary care. $(\mathrm{J}$ Am Board Fam Med 2018;31:73-82.)

Keywords: Cross-Sectional Studies, Electronic Cigarettes, Patient Preference, Primary Health Care, Secondhand Smoke, Self Report, Tobacco Products

Electronic cigarettes (e-cigarettes), which are noncombustible, battery-operated devices that deliver aerosolized nicotine, have become increasingly

\footnotetext{
This article was externally peer reviewed.

Submitted 22 May 2017; revised 9 September 2017; accepted 23 September 2017.

From the Department of Family and Preventive Medicine, Stephenson Cancer Center, University of Oklahoma Health Sciences Center, Oklahoma City, OK (MPD); Saint Anthony Shawnee Hospital, Shawnee, OK (MW); Variety Care, Oklahoma City (ER); University of Oklahoma, Norman, OK (ASK); University of Oklahoma Health Sciences Center, Oklahoma City, OK (DAR).

Funding: This work was supported in part by the Oklahoma Tobacco Research Program Summer Scholars Research Program, Stephenson Cancer Center.

Conflict of interest: none declared.

Corresponding author: Mark P. Doescher, MD, MSPH, 655 Research Parkway, Room 448, Oklahoma City, OK 73104 (E-mail: mdoesche@ouhsc.edu).
}

popular. ${ }^{1-5}$ In $2014,12.6 \%$ of adults in the United States reported that they had tried an e-cigarette at least once and $47.6 \%$ of current smokers had done so. ${ }^{1}$ Even among adults who had never smoked cigarettes, $3.2 \%$ reported that they had ever tried an e-cigarette. This figure rose to $9.7 \%$ among never smokers ages 18 to 24 years. ${ }^{1}$

Many people who use e-cigarettes, also known as vaping, may do so to reduce their exposure to the harmful constituents of conventional tobacco or to help them quit smoking tobacco products. ${ }^{6-9} \mathrm{Al}-$ though some evidence indicates that e-cigarettes may be less harmful than combustible tobacco products, e-cigarettes may still cause adverse health effects. ${ }^{10-12}$ E-cigarettes also typically contain nicotine, and could lead to nicotine addiction, raising the concern that they may serve as a gateway to 
more damaging tobacco products among youth and young adults. ${ }^{13-17}$

As has been the case for cigarettes and other tobacco products, patient views on e-cigarettes may be influenced by marketing. The vast majority of e-cigarette manufacturers and retailers market online, and $65 \%$ of online advertisements made at least 1 health-related claim in $1 \mathrm{study}^{18}$ and $77 \%$ in another. ${ }^{19}$ Among these claims, the reduction in secondhand smoke compared with combustible tobacco was most often cited, with an average of 2 claims per Web site. ${ }^{20}$

Given the emergence of widespread use of e-cigarettes and the frequency of health claims being made by the e-cigarette industry, surprisingly little is known about how patients and primary care providers (PCPs) discuss e-cigarettes during clinic visits. PCPs are in an ideal position to counsel patients about e-cigarette use, as $83 \%$ of US adults in 2013 reported having a physician office visit in the preceding 12 months and $53 \%$ of these visits were with PCPs. ${ }^{21}$ Furthermore, many PCPs routinely discuss tobacco use with their patients by following the United States Preventive Services Taskforce guideline recommending that clinicians ask all adults about tobacco use, advise them to stop using tobacco, and provide behavioral interventions and approved pharmacotherapy for cessation to adults who use tobacco. However, the Taskforce also concludes that evidence currently is insufficient to recommend e-cigarettes for tobacco cessation in adults and this group has not yet made a statement on screening for e-cigarette use. ${ }^{22}$ Thus, the role of PCPs in advising patients regarding the health risks or potential benefits of using e-cigarettes remains unclear at the same time that many patients are using these products and undoubtedly asking their PCPs about them.

A few studies have begun to explore how e-cigarettes are being addressed in primary care. In 1 study, $86 \%$ of PCPs reported that they screened for tobacco use regularly among adolescents, but only $14.5 \%$ of them screened for e-cigarette use. ${ }^{23}$ PCPs were also much less likely to discuss e-cigarette avoidance $(18 \%)$ than tobacco avoidance $(78 \%){ }^{24}$ One study showed that an informational and motivational group intervention resulted in a significant increase in perceived harm and reduced intention to use e-cigarettes and other tobacco products. ${ }^{24}$ However, this was a group intervention that took about 40 minutes, so does not directly apply to the typical primary care setting. A study in an Alaska Native health care setting showed that community members felt that PCPs were failing to address e-cigarettes and that the standard screening asked only about conventional tobacco products. ${ }^{25}$ The same study showed that patients generally felt that use of ecigarettes is a safer alternative than use of conventional tobacco products. On the other hand, providers interviewed in that same study felt that switching from cigarettes to e-cigarettes was merely substituting " 1 negative health behavior for another" without a positive impact on health. ${ }^{25}$

Because evidence-based recommendations about how to address e-cigarettes in primary care are lacking and studies investigating patients' preferences in counseling about use of e-cigarettes by their PCPs are quite limited, we conducted a clinicbased survey of adult primary care patients to investigate patients' perceived knowledge about ecigarettes, patient impressions regarding PCP knowledge about e-cigarettes and views on the role of the PCP in counseling about these products. We hypothesized that more patients than not would perceive their PCPs as having limited knowledge about e-cigarettes, and that many patients would want their PCPs to discuss e-cigarettes with them.

\section{Methods \\ Design and Study Population}

This study was conducted during the summer of 2016 at the Family Medicine Center of the University of Oklahoma Health Sciences Center. This clinic is a large, university-based, full-spectrum family medicine practice with 36 resident physicians, 17 supervising faculty members, a sports medicine fellowship, physician assistants, and nurse practitioners. In fiscal year 2015 the clinic recorded over 50,000 physician visits. Roughly $60 \%$ of the patients had health insurance coverage through Medicaid, 20\% had coverage through Medicare, and the remainder had coverage through private coverage or no insurance coverage. Resident physicians accounted for $70 \%$ of the visits. Almost all the clinic patients speak English as their primary language. The study was approved by the University of Oklahoma Health Sciences Center Institutional Review Board.

Over a 3-month period, adult patients waiting for their clinic appointment were approached in the waiting room by a member of the study team (AK). 
Efforts were made to approach all patients regardless of sex. Patients who agreed to participate were included if they were 18 years of age and spoke English. The final sample size was 568. We did not measure how many potential participants declined to complete the survey, so the overall response rate could not be determined; however, nearly all patients in the waiting rooms who were approached about the study agreed to participate. Participants did not receive payment or any other form of compensation for completing the survey.

The survey was a brief, approximately 10 -minute, anonymous, self-completed instrument written at the sixth grading reading level. To ensure that all participants were aware that the survey focused on e-cigarettes and related nicotine vapor devices (as opposed to marijuana or other substances), the description of the survey that was given to all potential participants included the sentence, "This survey is about electronic cigarettes and related nicotine vapor ('vaping') devices."

\section{Measures}

The authors searched the e-cigarette literature for previously validated questions pertinent to discussing e-cigarettes in primary care. However, no suitable questions were identified. Thus the authors created the survey and iteratively pilot tested it on 10 participants. The final version of the survey included 18 questions (Appendix) that used a Likert scale when appropriate, and included the following domains 1): E-cigarette use status categorized as: recent (use of e-cigarettes within the preceding 30 days), nonrecent (prior use of e-cigarettes, but not within the preceding 30 days), or never; 2 ) sociodemographic and lifestyle factors (age, sex, educational attainment, self-reported health status (excellent, very good, good, fair poor), and cigarette smoking status; 3 ) sources of information on e-cigarettes (television, family or friends, e-cigarette/ vape shops, radio, magazines, physician offices); 4) perceived knowledge about effects of e-cigarettes on health, secondhand smoke, and quitting cigarettes; 5) perceptions regarding PCP's knowledge about e-cigarettes; 6 ) level of comfort or interest in having the PCP discuss e-cigarettes with them; and, 7) how such a discussion might be formatted (no discussion, brief discussion, pamphlet/handout, dedicated office visit, group discussion, other or did not respond).

\section{Data Analysis}

To test for associations between the independent measures and e-cigarette status, $\chi^{2}$ analyses were completed setting a 2-tailed cutoff for statistical significance at $P<.05$ using SPSS software suite (v23; IBM Corp., Armonk, NY). Missing data were excluded for individual variables, and noted when this occurred.

\section{Results}

Women comprised $72.5 \%$ of the sample, and $50.3 \%$ of the sample was aged 18 to 44 years and $49.7 \%$ aged 45 years or older. Most (93\%) of the respondents had heard about e-cigarettes. Table 1 shows that $10 \%$ of respondents were recent e-cigarette users, while $29 \%$ were nonrecent users. Table 1 also reveals statistically significant differences in e-cigarette status by age $(P<.001)$, education $(P=.008)$, and cigarette-smoking status $(P<.001)$, but not by sex $(P=.680)$ or self-reported health $(P=.539)$. Younger participants were most likely to report recent e-cigarette use. Participants with lower levels of educational attainment were most likely to report recent or nonrecent e-cigarette use. Cigarette smoking status was strongly associated with e-cigarette use $(P<.001)$. Among the $28.4 \%$ of the participants classified as currently smoking cigarettes, $74.5 \%$ had tried e-cigarettes, and $21.7 \%$ reported recent use of e-cigarettes. Among the $22.0 \%$ who formerly smoked cigarettes, $36.8 \%$ had ever used e-cigarettes and $11.2 \%$ had recently used them. However, even among the $49.6 \%$ classified as never having smoked cigarettes, $15.7 \%$ were nonrecent users of e-cigarettes and $2.5 \%$ were recent users of e-cigarettes.

Table 2 shows that $27.3 \%$ of respondents agreed with the statement that they were knowledgeable about the effects of e-cigarettes on health, 30.7\% endorsed that they felt knowledgeable about secondhand smoke emitted from these devices, and $27 \%$ agreed that they felt knowledgeable about effects of e-cigarettes on quitting cigarettes. No statistically significant differences were observed by e-cigarette use category for any of these measures of e-cigarette knowledge (effects on health, $P=$ .335 ; secondhand smoke, $P=.069$; effect on quitting cigarettes, $P=.33$ ).

Respondents were asked where they had heard about e-cigarettes and Figure 1 shows that advertisements on television and word of mouth from 


\begin{tabular}{|c|c|c|c|c|c|}
\hline & \multicolumn{3}{|c|}{$\begin{array}{c}\text { When Was the Last Time You Smoked an Electronic } \\
\text { Cigarette/, Even One or Two Puffs? }\end{array}$} & \multirow[b]{2}{*}{$\begin{array}{l}\text { Total, } \mathrm{N} \\
(\%)\end{array}$} & \multirow[b]{2}{*}{$P$-Value } \\
\hline & $\begin{array}{l}\text { Recent Users, } \\
\text { N (\%) }\end{array}$ & $\begin{array}{l}\text { Nonrecent Users, } \\
\text { N (\%) }\end{array}$ & $\begin{array}{l}\text { Never Users, } \\
\quad \mathrm{N}(\%)\end{array}$ & & \\
\hline \multicolumn{6}{|c|}{ Age, years $($ missing $=2)$} \\
\hline 18 to 29 & $17(30.4)$ & $43(26.1)$ & $59(17.1)$ & $119(21.0)$ & \multirow[t]{4}{*}{$<.001$} \\
\hline 30 to 44 & $14(25.0)$ & $62(37.6)$ & $90(26.1)$ & $166(29.3)$ & \\
\hline 45 to 64 & $22(39.3)$ & $48(29.1)$ & $106(30.7)$ & $176(31.1)$ & \\
\hline $65+$ & $3(5.4)$ & $12(7.3)$ & $90(26.1)$ & $105(18.6)$ & \\
\hline \multicolumn{6}{|l|}{ Sex $(\operatorname{missing}=5)$} \\
\hline Male & $16(28.6)$ & $49(29.9)$ & $90(26.2)$ & $155(27.5)$ & \multirow[t]{2}{*}{.68} \\
\hline Female & $40(71.4)$ & $115(70.1)$ & $253(73.8)$ & $408(72.5)$ & \\
\hline \multicolumn{6}{|c|}{ Educational attainment $($ missing $=2)$} \\
\hline Grade 11 or Less & $9(16.1)$ & $17(10.2)$ & $44(12.8)$ & $70(12.4)$ & \multirow[t]{4}{*}{.008} \\
\hline Grade 12 or GED & $23(41.1)$ & $66(39.8)$ & $91(26.5)$ & $180(31.8)$ & \\
\hline Some college & $18(32.1)$ & $53(31.9)$ & $115(33.4)$ & $186(32.9)$ & \\
\hline College grad + & $6(10.7)$ & $30(18.1)$ & $94(27.3)$ & $130(23.0)$ & \\
\hline \multicolumn{6}{|c|}{ Self-reported general health (missing $=0$ ) } \\
\hline Excellent & $5(8.8)$ & $15(9.1)$ & $39(11.3)$ & $59(10.4)$ & \multirow[t]{5}{*}{.539} \\
\hline Very good & $12(21.1)$ & $27(16.4)$ & $75(21.7)$ & $114(20.1)$ & \\
\hline Good & $20(35.1)$ & $64(38.8)$ & $134(38.7)$ & $218(38.4)$ & \\
\hline Fair & $14(24.6)$ & $48(29.1)$ & $82(23.7)$ & $144(25.4)$ & \\
\hline Poor & $6(10.5)$ & $11(6.7)$ & $16(4.6)$ & $33(5.8)$ & \\
\hline \multicolumn{6}{|c|}{ Cigarette smoking $($ missing $=4$ ) } \\
\hline Current & $35(62.5)$ & $88(53.7)$ & $38(11.0)$ & $161(28.4)$ & \multirow[t]{3}{*}{$<.001$} \\
\hline Former & $14(25.0)$ & $32(19.5)$ & $79(22.8)$ & $125(22.0)$ & \\
\hline Never & $7(12.5)$ & $44(26.8)$ & $230(66.3)$ & $281(49.6)$ & \\
\hline
\end{tabular}

friends and family represented the 2 largest sources of this information $(56.6 \%$ and $49.9 \%$, respectively). Respondents also obtained information about these devices from e-cigarette (vape) shops fairly often $(25.5 \%)$. Fewer respondents reported hearing about e-cigarettes from radio or print advertisements (18\% and 16\%, respectively). Only $6 \%$ of respondents obtained information from a physician's office.

Table 3 presents participants' perspectives on the role of the PCP in discussing e-cigarettes. Roughly one third $(30.2 \%)$ of the respondents agreed with the statement that their PCP knew a lot about e-cigarettes, yet nearly two thirds $(62.0 \%)$ agreed with the statement that they felt comfortable talking with their PCP about e-cigarettes. Roughly one quarter $(24.7 \%)$ wanted their PCP to talk with them about these products, although the percentage of patients who wanted their PCP to talk with them about e-cigarettes increased to nearly two thirds (62.0\%) among recent e-cigarette users $(P<.001)$. Respondents were additionally asked about their preferred mode of receiving e-cigarette information (data not shown). For those who wanted information from PCP, a brief discussion and pamphlets/handouts were the preferred formats. Very few respondents $(<5 \%)$ wanted a dedicated clinic visit to discuss e-cigarettes, either in a private or group visit setting.

\section{Discussion}

Despite the rising popularity of e-cigarettes, research on how the primary care setting could provide information to patients regarding e-cigarettes has been strikingly limited. More than one third of our primary care respondents had previously tried or were currently using e-cigarettes, consistent with the rising use of e-cigarettes use in the US. ${ }^{1-5,26}$ However, $18 \%$ of the e-cigarette users had never smoked cigarettes, suggesting that some adults may be trying e-cigarettes for reasons other than to stop or reduce smoking.

Despite the fact that the effects of e-cigarettes on health and smoking cessation are not yet well 


\begin{tabular}{|c|c|c|c|c|}
\hline & \multicolumn{3}{|c|}{$\begin{array}{c}\text { When Was the Last Time You Smoked an Electronic } \\
\text { Cigarette, Even One or Two Puffs? }\end{array}$} & \multirow[b]{2}{*}{ Total } \\
\hline & $\begin{array}{l}\text { Recent Users, } \\
\text { N (\%) }\end{array}$ & $\begin{array}{l}\text { Nonrecent Users, } \\
\text { N (\%) }\end{array}$ & $\begin{array}{l}\text { Never Users, } \\
\quad \text { N }(\%)\end{array}$ & \\
\hline & $57(10.0)$ & $165(29.0)$ & $346(60.9)$ & $568(100)$ \\
\hline \multicolumn{5}{|c|}{$\begin{array}{l}\text { I am knowledgeable about the effect of electronic } \\
\text { cigarettes on users' health (missing }=40)\end{array}$} \\
\hline Strongly or somewhat agree & $15(29.4)$ & $52(32.1)$ & $77(24.4)$ & $144(27.3)$ \\
\hline Neither agree nor disagree & $14(27.5)$ & $40(24.7)$ & 75 (23.8.) & $129(24.4)$ \\
\hline Somewhat or strongly disagree & $22(43.1)$ & $70(43.2)$ & $163(51.7)$ & $255(48.3)$ \\
\hline \multicolumn{5}{|c|}{$\begin{array}{l}\text { I am knowledgeable about secondhand smoke } \\
\text { from electronic cigarettes (missing }=40)\end{array}$} \\
\hline Strongly or somewhat agree & $18(35.3)$ & $61(37.4)$ & $83(26.4)$ & $162(30.7)$ \\
\hline Neither agree nor disagree & $14(27.4)$ & $35(21.5)$ & $70(22.3)$ & $119(22.5)$ \\
\hline Somewhat or strongly disagree & $19(37.3)$ & $67(41.1)$ & $161(51.3)$ & $247(46.8)$ \\
\hline \multicolumn{5}{|c|}{$\begin{array}{l}\text { I am knowledgeable about the effects of } \\
\text { electronic cigarettes on quitting cigarettes } \\
\text { (missing }=56 \text { ) }\end{array}$} \\
\hline Strongly or somewhat agree & $16(31.4)$ & $48(30.2)$ & $74(24.5)$ & $138(27.0)$ \\
\hline Neither agree nor disagree & $8(15.7)$ & $40(25.2)$ & $82(27.2)$ & $130(25.3)$ \\
\hline Somewhat or strongly disagree & $27(52.9)$ & $71(44.6)$ & $146(48.3)$ & $244(47.7)$ \\
\hline
\end{tabular}

understood $^{27}$, roughly one quarter of the participants agreed that they were knowledgeable about the health effects of e-cigarettes, and similar percentages agreed that they were knowledgeable about secondhand smoke from e-cigarettes and their effects on quitting cigarettes. This is consistent with findings from another study in which roughly one quarter to one half of e-cigarette users reported the belief that e-cigarettes have no health risks. ${ }^{26}$ Marketing contributes to perceived knowledge regarding the health and safety of e-ciga- rettes $^{28}$, and in our sample, participants heard about e-cigarettes from the media, family or friends, and e-cigarette (vape) shops, but very few heard about them from physician offices, which is consistent with other research. ${ }^{29}$ These findings underscore the need for PCPs to be able to provide patients with accurate information on these products rather than relying on potentially biased and profit-driven sources of information.

Despite the lack of information on e-cigarettes obtained by patients from physicians, one fourth of

Figure 1. Patients' reported sources of information about e-cigarettes in $2016(\mathrm{~N}=532)$.

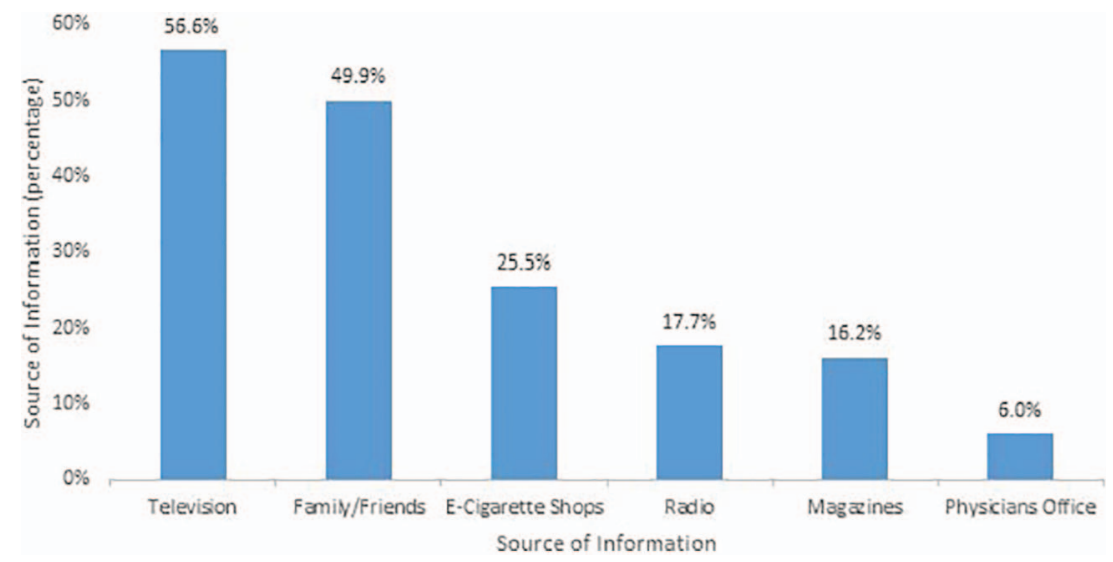




\begin{tabular}{|c|c|c|c|c|c|}
\hline & \multicolumn{3}{|c|}{$\begin{array}{l}\text { When Was the Last Time you Smoked an } \\
\text { e-Cigarette, Even One or Two Puffs? }\end{array}$} & \multirow[b]{2}{*}{$\begin{array}{c}\text { Total, } \mathrm{N} \\
(\%)\end{array}$} & \multirow[b]{2}{*}{$P$-Value } \\
\hline & $\begin{array}{l}\text { Recent Users, } \\
\text { N (\%) }\end{array}$ & $\begin{array}{l}\text { Nonrecent Users, } \\
\text { N (\%) }\end{array}$ & $\begin{array}{l}\text { Never Users, } \\
\text { N (\%) }\end{array}$ & & \\
\hline \multicolumn{6}{|c|}{$\begin{array}{l}\text { My primary care provider knows a lot about } \\
\text { electronic cigarettes (missing }=71 \text { ) }\end{array}$} \\
\hline strongly or somewhat disagree & $8(16.3)$ & $22(14.3)$ & $38(12.9)$ & $68(13.7)$ & .905 \\
\hline neither disagree nor agree & $27(55.1)$ & $89(57.8)$ & $163(55.5)$ & $279(56.1)$ & \\
\hline somewhat or strongly agree & $14(28.6)$ & $43(27.9)$ & $93(31.6)$ & $150(30.2)$ & \\
\hline \multicolumn{6}{|c|}{$\begin{array}{l}\text { I am comfortable discussing electronic cigs with } \\
\text { my primary care provider (missing }=49 \text { ) }\end{array}$} \\
\hline strongly or somewhat disagree & $4(7.8)$ & $28(17.5)$ & $49(15.9)$ & $81(15.6)$ & .161 \\
\hline neither disagree nor agree & $8(15.7)$ & $32(20.0)$ & $76(24.7)$ & $116(22.4)$ & \\
\hline somewhat or strongly agree & $39(76.5)$ & $100(62.5)$ & $183(59.4)$ & $322(62.0)$ & \\
\hline \multicolumn{6}{|c|}{$\begin{array}{l}\text { Would you want your PCP to discuss cigarettes } \\
\text { electronic with you during your clinic } \\
\text { visits? (missing }=47 \text { ) }\end{array}$} \\
\hline Yes & $31(62.0)$ & $50(30.9)$ & $53(16.1)$ & $134(24.7)$ & $<.001$ \\
\hline No & $19(38.0)$ & $112(69.1)$ & $276(83.9)$ & $407(75.3)$ & \\
\hline
\end{tabular}

PCP, primary care provider.

all participants would want PCPs to discuss e-cigarettes with them, a figure that rises to nearly two thirds of recent e-cigarette users. Yet less than one third of respondents agreed with the statement that their PCP knows a lot about e-cigarettes. The few reports on e-cigarette counseling by PCPs indicate that when counseling occurs, it tends to be in the context of recommended e-cigarettes as a cigarette cessation aid $^{29-31}$, despite the fact that little evidence exists that e-cigarettes are effective in smoking cessation ${ }^{7,8}$ and may even be associated with fewer quit attempts in "real-world" clinical settings. ${ }^{32}$ It seems inevitable that PCPs will increasingly discuss e-cigarettes with patients, so efforts to better characterize the possible role of e-cigarettes on smoking behaviors, such as cigarette cessation are needed, as is research to help provide PCPs with evidence-based information on these products. However, given the uncertainty about e-cigarette benefits versus harms, e-cigarette counseling should perhaps be predominately educational, at least for now. The counseling could explain that currently there is very little evidence-based information regarding the relative benefits versus harms of e-cigarettes regarding their effectiveness as smoking cessation aids or their role in serving as a gateway to more harmful tobacco products. Respondents who were interested in hearing about e-cigarettes strongly preferred brief discussion or pamphlets/handouts to dedicated office visits or group discussions. If used for e-cigarettes, the approach of screening patients and providing brief counseling would align well with a variety of evidence-based, health behavior interventions delivered in the primary care setting, including screening for depression ${ }^{33}$, alcohol misuse ${ }^{34}$, and smoking/tobacco use. ${ }^{35}$ For those with positive screens for e-cigarette use, brief conversations in the primary care setting or referral for specialized services could lead to effective behavior change, as has been demonstrated for a variety of health behaviors.

One limitation of the study is convenience sampling resulting in potential selection bias. To mitigate this issue, we attempted to recruit all patients meeting eligibility criteria who were present on the days in which recruitment occurred, most of whom agreed to participate. The age and sex distribution of the final sample reflects that of our clinic, which has high numbers of younger women with Medicaid insurance coverage. To help maximize survey participation and completion, we opted to keep the survey as brief as possible, so we did not include questions on several factors that might be related to patient perceptions regarding e-cigarettes, such as income, race and ethnicity, health literacy, past tobacco cessation attempts, use of e-cigarettes for tobacco cessation, length of time having been seen at the clinic, duration of relationship with PCP, etc. Our sampling frame included all adults being seen for primary care in our setting regardless of their 
use of e-cigarettes or other tobacco/nicotine products. Additional research would be needed to gain an understanding of e-cigarette use among adolescents and to identify interventions for addressing e-cigarette use in this segment of the population. Additional research on the subset of patients who currently use e-cigarettes would be needed to explore the underlying reasons why individuals use these products and whether these reasons differ for those who additionally use other tobacco/nicotine products compared with those who use e-cigarettes exclusively. Also, we did not have sufficient sample size in this preliminary research to be able to perform detailed subgroup analysis by e-cigarette use category. Future research would be needed to explore patients' perception about the role of PCPs in ecigarette counseling among specific groups of e-cigarette users. Some participants did not complete the entire survey because they were called in from the waiting room where the survey was being administered to their examination room before completing the survey. This explains the progressive decline in sample size presented in each table. Finally, the Midwest and South, including Oklahoma, have a high prevalence of e-cigarette use $\mathrm{u}^{3}$, so the prevalence of e-cigarette uptake in our setting may not apply in other locations, although the upward trend in e-cigarette use nationally suggests that other locations in the United States may soon resemble this part of the country. This study did not collect information on adolescents.

This study has identified the high prevalence of e-cigarette use in a primary care setting and suggests the need for PCPs to assess for e-cigarette use and provide patients with accurate information about e-cigarettes. Given the increasing prevalence of e-cigarette use, we suggest that an approach in primary care that routinely screens for e-cigarette use and provides brief counseling to those who vape may be reasonable, although further research in this area is needed. It might also be reasonable to screen for those who intend to use e-cigarettes, including current smokers. Our findings suggest that patients may be receptive to this approach, which is consonant with what is done for cigarette smoking. However, the content and format of e-cigarette counseling need to be determined. Clearly, the discipline of primary care would benefit from a concerted effort to develop, test, and implement evidence-based e-cigarette interventions.

To see this article online, please go to: http://jabfm.org/content/ 31/1/73.full.

\section{References}

1. Schoenborn CA, Gindi RM. Electronic Cigarette use among adults: United States, 2014. NCHS Data Brief. 2015;1-8.

2. McMillen RC, Gottlieb MA, Shaefer RM, Winickoff JP, Klein JD. Trends in electronic cigarette use among U.S. adults: Use is increasing in both smokers and nonsmokers. Nicotine Tob Res 2015;17:1195202.

3. King BA, Patel R, Nguyen KH, Dube SR. Trends in awareness and use of electronic cigarettes among US adults, 2010-2013. Nicotine Tob Res 2015;17:21927.

4. McMillen R, Maduka J, Winickoff J. Use of emerging tobacco products in the United States. J Environ Public Health 2012;2012:989474.

5. Pearson JL, Richardson A, Niaura RS, Vallone DM, Abrams DB. E-Cigarette awareness, use, and harm perceptions in US adults. Am J Public Health 2012; 102:1758-66.

6. McNeill A, Brose LS, Calder R, Hitchman SC. Ecigarettes: an evidence update. 2015. Public Health England. 2015. Available from: https://www.gov.uk/ government/uploads/system/uploads/attachment_ data/file/457102/Ecigarettes_an_evidence_update_ A_report_commissioned_by_Public_Health_England_ FINAL.pdf. Accessed Dec 3, 2016.

7. McRobbie H, Bullen C, Hartmann-Boyce J, Hajek P. Electronic cigarettes for smoking cessation and reduction. Cochrane Database Syst Rev 2014;(12): CD010216.

8. Malas M, van der Tempel J, Schwartz R, et al. Electronic cigarettes for smoking cessation: A systematic review. Nicotine Tob Res 2016;18:1926-36.

9. Rahman MA, Hann N, Wilson A, Worrall-Carter L. Electronic cigarettes: Patterns of use, health effects, use in smoking cessation and regulatory issues. Tob Induc Dis 2014;12:21.

10. Kuschner WG, Reddy S, Mehrotra N, Paintal HS. Electronic cigarettes and thirdhand tobacco smoke: Two emerging health care challenges for the primary care provider. Int J Gen Med 2011;4:115-20.

11. Jensen RP, Luo W, Pankow JF, Strongin RM, Peyton DH. Hidden formaldehyde in e-cigarette aerosols. N Engl J Med 2015;372:392-4.

12. Yu V, Rahimy M, Korrapati A, et al. Electronic cigarettes induce DNA strand breaks and cell death independently of nicotine in cell lines. Oral Oncol 2016;52:58-65.

13. Dutra LM, Glantz SA. Electronic cigarettes and conventional cigarette use among U.S. adolescents: 
A cross-sectional study. JAMA Pediatr 2014;168: 610-7.

14. Bunnell RE, Agaku IT, Arrazola RA, et al. Intentions to smoke cigarettes among never-smoking US middle and high school electronic cigarette users: National Youth Tobacco Survey, 2011-2013. Nicotine Tob Res 2015;17:228-35.

15. Wills TA, Sargent JD, Knight R, Pagano I, Gibbons FX. E-cigarette use and willingness to smoke: A sample of adolescent non-smokers. Tobacco control 2016;25(e1):e52-9.

16. Leventhal AM, Strong DR, Kirkpatrick MG, et al. Association of electronic cigarette use with initiation of combustible tobacco product smoking in early adolescence. JAMA 2015;314:700-7.

17. Sutfin EL, Reboussin BA, Debinski B, Wagoner KG, Spangler J, Wolfson M. The impact of trying electronic cigarettes on cigarette smoking by college students: A prospective analysis. Am J Public Health 2015;105(8):e83-e89.

18. Laverty AA, Vardavas CI, Filippidis FT. Design and marketing features influencing choice of e-cigarettes and tobacco in the EU. Eur J Public Health 2016; 26:838-41.

19. Basch CH, Mongiovi J, Hillyer GC, Ethan D, Hammond R. An analysis of electronic cigarette and cigarette advertising in us women's magazines. Int J Prev Med 2016;7:103.

20. Klein EG, Berman M, Hemmerich N, Carlson C, Htut S, Slater M. Online e-cigarette marketing claims: A systematic content and legal analysis. Tob Regul Sci 2016;2:252-62.

21. National Ambulatory Med Care Survey: 2013 State and National Summary Tables. Available from: http://www.cdc.gov/nchs/ahcd/ahcd_products.htm. Accessed May 25, 2017.

22. U.S. Preventive Services Task Force. Final update summary: Tobacco smoking cessation in adults, including pregnant women: Behavioral and pharmacotherapy interventions, September 2015. Available from: https://www.uspreventiveservicestaskforce. org/Page/Document/UpdateSummaryFinal/tobaccouse-in-adults-and-pregnant-women-counselingand-interventions 1 ?ds $=1 \& s=$ tobacco. Accessed August 22, 2017.

23. Pepper JK, Gilkey MB, Brewer NT. Physicians' counseling of adolescents regarding e-cigarette use. J Adol Health 2015;57:580-6.
24. Little MA, Talcott GW, Bursac Z, et al. Efficacy of a brief tobacco intervention for tobacco and nicotine containing product use in the US Air Force. Nicotine Tob Res 2016;18:1142-9.

25. Hiratsuka VY, Avey JP, Trinidad SB, Beans JA, Robinson RF. Views on electronic cigarette use in tobacco screening and cessation in an Alaska Native healthcare setting. Int J Circumpolar Health 2015; $74: 27794$.

26. Zhuang YL, Cummins SE, J YS, Zhu SH. Longterm e-cigarette use and smoking cessation: a longitudinal study with US population. Tobacco control 2016;25(Suppl 1):i90-i95.

27. Dinakar C, O'Connor GT. The health effects of electronic cigarettes. N Engl J Med 2016;375: $1372-81$.

28. Gowin M, Cheney MK, Wann TF. Knowledge and beliefs about e-cigarettes in straight-to-work young adults. Nicotine Tob Res 2017;19:208-14.

29. Kollath-Cattano C, Thrasher JF, Osman A, Andrews JO, Strayer SM. Physician advice for e-cigarette use. J Am Board Fam Med 2016;29:741-7.

30. Kandra KL, Ranney LM, Lee JG, Goldstein AO. Physicians' attitudes and use of e-cigarettes as cessation devices, North Carolina, 2013. PloS One 2014; 9(7):e103462.

31. Steinberg MB, Giovenco DP, Delnevo CD. Patientphysician communication regarding electronic cigarettes. Prev Med Rep 2015;2:96-8.

32. Kalkhoran S, Glantz SA. E-cigarettes and smoking cessation in real-world and clinical settings: A systematic review and meta-analysis. Lancet Respir Med 2016;4:116-28.

33. O'Connor EA, Whitlock EP, Beil TL, Gaynes BN. Screening for depression in adult patients in primary care settings: A systematic evidence review. Ann Intern Med 2009;151:793-803.

34. O'Donnell A, Anderson P, Newbury-Birch D, et al. The impact of brief alcohol interventions in primary healthcare: A systematic review of reviews. Alcohol Alcohol 2014;49:66-78.

35. Fiore MC, Jaén CR, Baker TB. Treating tobacco use and dependence: 2008 update. Clinical Practice Guideline. Rockville, MD: U.S. Department of Health and Human Services; May 2008. 
Today's Date: _ $\quad$ /_ /

ID\# (Office use only)

Below are a few questions aimed at better understanding what you, a patient in our clinic, know about e-cigarettes/vaping, as well as your views on the role your PCP plays in furthering that knowledge base. Please fill out all the questions on this survey to the best of your ability.

1. How old are you?
18 to 29
30 to 44
45 to 64
$65+$

2. What is your sex?

Male

Female

3. Which of the following best describes your education level?

Grade 11 or less (elementary, middle or high school)

Grade 12 or GED

Some college

College graduate/post-graduate degree

4. What would you say is your general health?

Excellent

Very good

Good

Fair

Poor

5. Have you smoked at least $\mathbf{1 0 0}$ cigarettes in your entire life?

Yes

No

6. How often do you currently smoke cigarettes?

Every day

Some days

Not at all
7. Have you heard about e-cigarettes or vaping?

Yes

No

8. Have you ever used an e-cigarette or vaped even one or two times? Yes

No

9. When was the last time you smoked an e-cigarette/vaped, even one or two puffs?

I have never used an e-cigarette, not even one or two puffs

Earlier today

Not today but sometime during the past 7 days

Not during the past 7 days but sometime during the past 30 days

Not during the past 30 days but sometime during the past year

1 or more years ago

10. Where have you obtained the information you have on ecigarettes/vaping (check all that apply)?

Advertisements on TV

Advertisements in magazines

Radio

Friends/Family

Vape/E-cigarette shops

Physician's office

Other (please

specify):

SURVEY CONTINUES ON NEXT PAGE 


\begin{tabular}{|l|l|l|l|l|l|}
\hline (MARK ONE BOX IN EACH ROW) & $\begin{array}{l}\text { Strongly } \\
\text { disagree }\end{array}$ & $\begin{array}{l}\text { Somewhat } \\
\text { disagree }\end{array}$ & $\begin{array}{l}\text { Neither } \\
\text { disagree } \\
\text { nor agree }\end{array}$ & $\begin{array}{l}\text { Somewhat } \\
\text { agree }\end{array}$ & $\begin{array}{l}\text { Strongly } \\
\text { agree }\end{array}$ \\
\hline $\begin{array}{c}\text { 11.I am knowledgeable about the } \\
\text { effects of e-cigarettes/vaping on } \\
\text { users' health. }\end{array}$ & & & & & \\
\hline $\begin{array}{c}\text { 12.I am knowledgeable about } \\
\text { secondhand smoke from e- } \\
\text { cigarettes/vaping. }\end{array}$ & & & & & \\
\hline $\begin{array}{c}\text { 13.I am knowledgeable about the } \\
\text { effects of e-cigarettes/vaping on } \\
\text { quitting cigarettes. }\end{array}$ & & & & & \\
\hline $\begin{array}{c}\text { 14.I am comfortable discussing e- } \\
\text { cigarettes/vaping with my } \\
\text { friends/family. }\end{array}$ & & & & & \\
\hline $\begin{array}{l}\text { 15.I am comfortable discussing e- } \\
\text { cigarettes/vaping with my primary } \\
\text { care provider. }\end{array}$ & & & & & \\
\hline $\begin{array}{c}\text { 16. My primary care provider knows a } \\
\text { lot about e-cigarettes. }\end{array}$ & & & & & \\
\hline
\end{tabular}

17. Would you want your primary care provider to discuss e-cigarettes/vaping with you during your clinic visits?

Yes

No

18. How would you prefer that your primary care provider discuss e-cigarettes/vaping with you?

I would not want my primary care provider to discuss e-cigarettes/vaping with me

Pamphlet/Handout

Brief discussion (1-3 minutes) during office visit

Dedicated office visit

Group discussion with other interested parties

Other (please

specify):

19. Comments:

THIS IS THE END OF THE SURVEY - THANK YOU! 